• 研究报告・

\title{
新疆塔什库尔干野生动物自然保护区 马可波罗盘羊潜在生态廊道识别
}

\author{
陈强强 1,2 李美玲1,3 王 旭 ${ }^{4}$ Faisal Mueen Qamer ${ }^{5}$ \\ 王 鹏 ${ }^{6}$ 杨建伟 ${ }^{6}$ 汪沐阳 ${ }^{1}$ 杨维康 $^{1^{*}}$ \\ 1 (中国科学院新疆生态与地理研究所中国科学院干早区生物地理与生物资源重点实验室, 乌鲁木齐 830011) \\ 2 (中国科学院大学, 北京 100049) \\ 3 (新疆大学资源与环境科学学院, 乌鲁木齐 830046) \\ 4 (新疆林业科学院, 乌鲁木齐 830063) \\ 5 (国际山地综合发展中心, 加德满都, 尼泊尔 999098) \\ 6 (塔什库尔干野生动物自然保护区管理局, 新疆喀什 844000)
}

摘要: 识别野生动物的适宜生境并在适宜生境之间构建生态廊道能够提高生境连通性, 有利于加强种群间基因交 流并缓解生境破碎化带来的不利影响。本研究基于生境适宜性评价结果确定了塔什库尔干野生动物自然保护区内 马可波罗盘羊(Ovis polii)的核心生境斑块, 运用廊道设计模型Linkage Mapper识别最低成本廊道并确定其优先级。 结果表明, 马可波罗盘羊适宜生境主要分布在保护区西北部, 核心生境斑块少且破碎化明显, 夏冬两季核心生境 斑块均为 28 个, 潜在生态廊道分别为 45 和 47 条。采用成本加权距离与欧几里得距离之比(CWD : EucD)以及成本加 权距离与最低成本路径长度之比(CWD : LCP)两种度量方法评估了生态廊道的质量与重要性。以CWD : EucD来衡 量, 夏季质量最高的4条廊道分别是皮斯岭至帕日帕克、同库至马尔洋、科克吐鲁克至帕日帕克, 以及哈尔努孜至 同库; 冬季质量最高的 3 条廊道分别是其克尔克尔至亚希洛夫、萨提曼至依西代尔、其克尔克尔至科克吐鲁克。 CWD : LCP分析表明, 夏季质量最高的廊道分别是哈尔努孜至阔克加尔和阔克加尔至马尔洋; 冬季质量最高的廊 道分别是爱勒米希至塔萨拉、沙尔比列西南至依西代尔。利用流中心性评估各核心生境斑块和廊道的重要性表明, 帕日帕克、塔萨拉和马尔洋这三个斑块在促进马可波罗盘羊迁移扩散方面的贡献值最高。夏季皮斯岭至帕日帕克、 同库至马尔洋和马拉特至其克尔克尔这3条廊道的贡献值最高; 冬季爱勒米希至塔萨拉、沙尔比列至沙尔比列西南 和铁尔布尔列至沙尔比列这 3 条廊道的贡献值最高, 上述核心生境斑块和生态廊道在维持保护区马可波罗盘羊种 群迁徙扩散中发挥着关键作用。此外, 赞坎、沙尔比列等斑块虽然面积小、贡献值低, 但起到了维持景观中重要 斑块连通的踏脚石作用, 其重要性也不可忽略。研究结果可为塔什库尔干野生动物保护区马可波罗盘羊有效保护、 保护区功能区划优化以及当地基础建设项目的规划选址提供科学指导。

关键词：马可波罗盘羊; 最小成本路径; 生境适宜性指数; 生态廊道; 塔什库尔干野生动物自然保护区

\section{Identification of potential ecological corridors for Marco Polo sheep in Taxkorgan Wildlife Nature Reserve, Xinjiang, China}

Qiangqiang Chen ${ }^{1,2}$, Meiling $\mathrm{Li}^{1,3}$, Xu Wang ${ }^{4}$, Faisal Mueen Qamer ${ }^{5}$, Peng Wang ${ }^{6}$, Jianwei Yang $^{6}$, Muyang Wang ${ }^{1}$, Weikang Yang ${ }^{1 *}$

1 CAS Key Laboratory of Biogeography and Bioresources in Arid Land, Xinjiang Institute of Ecology and Geography, Urumqi 830011, China

2 University of Chinese Academy of Sciences, Beijing 100049, China

3 College of Resources and Environment Science, Xinjiang University, Urumqi 830046, China

4 Xinjiang Academy of Forestry Sciences, Urumqi 830063, China

收稿日期: 2018-10-05; 接受日期: 2019-02-01

基金项目: 国家自然科学基金(31661143019; 41661144001)和国家重点研发计划(2016YFC0503307)

* 通讯作者 Author for correspondence. E-mail: yangwk@ms.xjb.ac.cn 
5 International Centre for Integrated Mountain Development, Kathmandu 999098, Nepal

6 Taxkorgan Wildlife Nature Reserve Administration, Kashi, Xinjiang 844000, China

Abstract: Identifying suitable habitats for wildlife and building corridors between those habitats increases the connectivity of suitable habitat patches, enhancing gene communication, and mitigating the adverse effects of habitat fragmentation. In this study, the core distribution areas of Marco Polo sheep (Ovis polii) were determined based on a suitability index model. The lowest cost corridors were then identified using the Linkage Mapper model and their priorities were determined. Results showed that the suitable habitats of Marco Polo sheep were mainly distributed in the northwestern areas of the Taxkorgan Wildlife Nature Reserve. A total of 28 core patches (CPs) (core patches were defined as habitat patches with an area of larger than $10 \mathrm{~km}^{2}$ in summer and $5 \mathrm{~km}^{2}$ in winter) were confirmed both in summer and winter, which is a lower number and demonstrates fragmentation of suitable habitat. In total, 45 and 47 potential corridors for Marco Polo sheep habitat were identified for summer and winter habitats, respectively. The ratio of the cost-weighted distance and the Euclidean distance ratio (CWD : EucD), and ratio of cost-weighted distance and the least-cost path length (CWD : LCP) were used to evaluate the quality and importance of each corridor. Using the CWD : EucD, the top four highest quality corridors in summer were Tongku to Maeryang, Keketuluke to Paripake, Pisiling to Paripake and Haernuzi to Tongku; the top three highest quality corridors in winter were Qikeerkeer to Yaxiluofu, Satiman to Yixidaier and Qikeerkeer to Keketuluke. In comparison, using the CWD : LCP, the only two highest quality corridors were identified in summer and winter, i.e. Haernuzi to Kuokejiaer and Kuokejiaer to Maeryang in summer and Ailemixi to Tasala, the southwest of Shaerbilie to Yixidaier in winter. Current flow centrality was used to evaluate the contribution of each core patch and corridor to facilitate sheep movement. The highest contributions were from patches in Paripake, Tasala and Maeryang in summer and patches Paripake, Tasala and Maeryang in winter. The highest corridors were between patches Tongku to Maeryang, Malate to Qikeerkeer and Pisiling to Paripake in summer, and Ailemixi to Tasala, Shaerbilie to the southwest of Shaerbilie and Tieerbuerlie to Shaerbilie in winter. These results suggest that the above-mentioned CPs and corridors play key roles in maintaining connectivity of Marco Polo sheep habitats. Patches such as Zancan and Shaerbilie that are small in area and contribution little, still play an important role in maintaining the connectivity of important patches in the landscape. The results of present study will optimize understanding of functional zones and improve management schemes for conservation of this endangered species in the Taxkorgan Nature Reserve.

Key words: Marco Polo sheep; least-cost path; habitat suitability index; ecological corridor; Taxkorgan Wildlife Nature Reserve

“野生动物生态廊道(wildlife corridor)”的概念 于1974年由Willis首次提出(Willis, 1974)。构建野生 动物生态廊道不仅有利于野生动物的迁徙扩散, 提 高生境斑块间的连接性, 还能促进濒危物种异质种 群间的基因交流、缓解生境破碎化造成的不利影响, 从而降低种群灭绝风险(Crooks \& Sanjayan, 2006; Lees \& Peres, 2008)。因此在过去十多年里有关野生 动物廊道识别、预测和建立的研究工作得到了迅猛 发展(Abrahms et al, 2017)。近年来, 国内外学者运 用最小成本路径原理(least-cost path theory)和电流 理论(circuit theory)开展了一系列具有代表性的濒 危物种生态廊道研究工作(Douglas-Hamilton et al, 2005; Dutta et al, 2016; 青菁等, 2016)。虽然有研究 证实只有部分野生动物个体利用廊道, 但廊道仍能 有效改善生境破碎化的负面效应(Feng et al, 2009)。 目前常用的廊道构建方法大多基于模型, 如专家意
见模型(Sawyer et al, 2011; 李维平等, 2017)、最小成 本路径分析(Adriaensen et al, 2003; 诸葛海锦等, 2015; Hashmi et al, 2017)、电流分析(Pelletier et al, 2014; Pierik et al, 2016)、基于个体的模型(Kanagaraj et al, 2013; Allen et al, 2016)、资源选择函数模型 (Boyce \& McDonald, 1999; Abrahms et al, 2017)、生 态位因子模型(Titeux et al, 2007)等, 但它们在应用 方面均存在一定的局限性。最小成本路径模型基于 图论测定多种空间运动过程, 反映了异质景观对某 种空间运动过程的综合阻力(Knaapen et al, 1992), 被认为是分析异质性景观连接性方面的一种有效 的、可操作的、灵活的方法(Adriaensen et al, 2003; Hashmi et al, 2017), 已经成为当前野生动物生态廊 道识别的主流方法, 被广泛应用于物种保护、自然保 护区规划、区域生态安全格局设计等景观优化工程。 马可波罗盘羊(又称帕米尔盘羊, Ovis polii)(蒋 
志刚等, 2015)分布于中国、阿富汗、塔吉克斯坦、 巴基斯坦和吉尔吉斯斯坦五国边境相邻的帕米尔 高原(Valdez et al, 2016), 在中国主要分布于塔什库 尔干野生动物自然保护区 (以下简称保护区), 是国 家II级重点保护野生动物, 《中国脊椎动物红色名 录》易危级物种(蒋志刚等, 2016)。近年来由于气候 变化以及人类活动加剧(过牧、矿业开发、过度狩猎、 盗猎等), 马可波罗盘羊生境破碎化严重, 种群数量 显著下降(王玉涛等，2016)。再加上国道314线穿越 保护区，居民定居点及其周围高强度的人类活动势 必严重影响该物种的生境连续性。因此开展马可波 罗盘羊的生境适应性分析, 有效识别该物种的潜在 生态廊道迫在眉睫。

基于上述原因, 本研究在开展马可波罗盘羊生 境质量评价的基础上, 运用Linkage Mapper软件 (McRae \& Kavanagh, 2011), 使用最小成本原理分 析识别其核心生境斑块间的潜在生态廊道，旨在探 讨以下问题: (1)马可波罗盘羊的核心生境斑块在保 护区是如何分布的? (2)核心生境斑块间是否有潜在 迁徙廊道分布? (3)哪些核心生境斑块和生态廊道在 维持马可波罗盘羊季节迁徙和基因交流方面非常 重要? 以期为相关保护管理部门构建生态廊道、维 持马可波罗盘羊生境连通性、实现该物种的有效保 护提供科学指导。

\section{研究区概况}

保护区位于中国新疆喀什地区，西部与巴基斯 坦、阿富汗、塔吉克斯坦三国接壤, 地理位置为

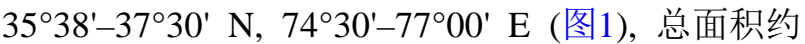
$15,836 \mathrm{~km}^{2}$, 是我国唯一以马可波罗盘羊为主要保 护对象的自然保护区(梁果栋, 1984)。该区域海拔最 高8,387 m, 最低 $2,074 \mathrm{~m}$, 平均海拔 4,000 $\mathrm{m}$ 以上, 地势高差悬殊，总体从西北向东南倾斜。该地区为 典型的大陆性高原干旱荒漠气候, 空气稀薄、日照 充足。气候极端寒冷干旱, 年均气温低于 $0^{\circ} \mathrm{C}$, 年均 降水量在70 mm左右。研究区内野生动植物资源 丰富, 分布有典型的高寒荒漠植物, 常见的植物有 紫花针茅(Stipa purpurea)、垫状驼线栳(Ceratoides compacta)、中麻黄(Ephedra intermedia)、南疆点地 梅(Androsace flavescens)、青藏薹草(Carex moorcroftii)等(龚明昊等, 2007)。保护区分布有雪豹 (Panthera uncia)、北山羊(Capra sibirica)、胡兀鹑

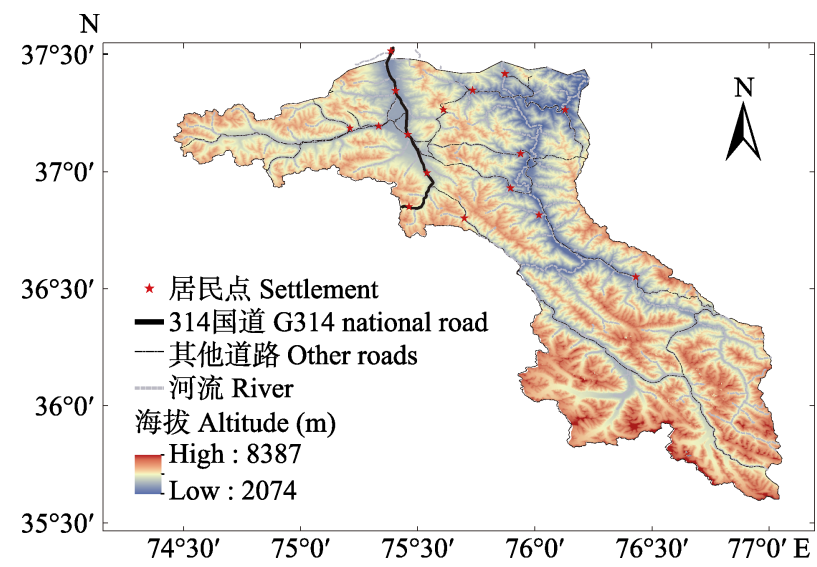

图1 塔什库尔干野生动物自然保护区位置

Fig. 1 Location of Taxkorgan Wildlife Nature Reserve

(Gypaetus barbatus)、金雕 (Aquila chrysaetos)等10种 国家I级重点保护动物, 以及马可波罗盘羊、豹 (Cuon alpinus)、藏原羚(Procapra picticaudata)、岩 羊 (Pseudois nayaur)、藏雪鸡 (Tetraogallus tibetanus)、暗腹雪鸡(T. himalayensis)、秃熟(Aegypius monachus)等25种国家II级重点保护动物(王玉涛等, 2016)。国道314线贯穿保护区西北部，两侧均有围 栏、防护林等人工设施，多数居民点亦沿该国道两 侧分布。

\section{研究方法}

\section{1 方法和原理}

首先，采用生境适宜性指数 (habitat suitability index, HSI)评估保护区内马可波罗盘羊的生境质量, 确定核心生境。其次, 基于生境质量确定阻力系数, 构建阻力图层。阻力系数表示物种个体穿过某一特 定的景观单元的意愿或对景观单元的适宜度(吴昌 广等, 2009)。在穿过特定环境的过程中, 如果物种 个体能量和时间消耗少, 死亡率低, 意味着该环境 阻力低, 则动物从该区域通过的可能性较大(Zeller et al, 2012)。最后，基于整合电流理论和最小成本路 径分析的Linkage Mapper程序(McRae \& Kavanagh, 2011)进行廊道识别分析。Linkage Mapper能够识别 相邻的核心区域，利用邻近的核心区域和距离数据 创建核心区域网络，计算成本加权距离和最小成本 路径，最后将成本最低的廊道组合成一张地图。

\section{2 数据收集与处理}

基于马可波罗盘羊的习性及生境需求，选取影 响其生境适宜性的关键因子，即海拔、坡度、坡向、 
植被类型、距水源距离、距道路距离、距居民点距 离。数据来源如下: (1)研究区域 $30 \mathrm{~m} \times 30 \mathrm{~m}$ 的海拔 数据来源于中国科学院计算机网络信息中心地理 空间数据云平台(http://www.gscloud.cn); 坡度、坡 向数据由本区域的数字高程经ArcGIS空间分析处 理得到; (2)植被类型矢量数据, 截取于 $1: 100$ 万植被 图; (3)道路、居民点、水系分布数据以及国界线矢 量数据均来源于 2017 版全国基础地理数据库; (4)保 护区边界与范围数据由保护区提供。

在开展马可波罗盘羊野外调查之前, 咨询当地 牧民和保护区工作人员, 初步确定其分布区域, 参 照保护区的地形地貌沿主要沟谷布设16条样线(陈 强强等, 2018)。2016-2017年沿样线驾车或徒步行进, 用 $8 \times 42$ 双筒望远镜和20-60倍单筒望远镜观测，发 现马可波罗盘羊后记录观测点的经纬度坐标、马可 波罗盘羊与观测点间的角度、距离。根据观测点经 纬度、距离以及夹角计算出马可波罗盘羊实际分布 位点的经纬度信息(宓春荣等, 2017)。统计盘羊实际 分布数据, 确定该物种对不同植被类型、地形因子 等的偏好性。

结合野外调查报告以及相关文献和专家建议 将不同的植被类型、海拔、坡度、坡向、坡位及距 水源距离按照马可波罗盘羊对其的适宜性分别赋 予不同的值。距居民点、道路的不同距离能够反映 人类活动对马可波罗盘羊的不同影响程度，因此本 研究针对道路和居民点建立不同等级的缓冲区, 并 为每个缓冲区赋值, 最终转化为栅格图层。相关方 法详见田波等(2008)和诸葛海锦等(2014)。前人研究 表明，马可波罗盘羊喜好植被密度较低的碎石地, 该类型生境中分布的主要物种为禾本科和莎草科 植物, 此外也有小丛红景天(Rhodiola rosea)和驼线 僽(Ceratoides latens); 马可波罗盘羊分布区域均远 离公路和居民点(余玉群等, 2008; 王玉涛等, 2016;

Salas et al, 2017)。

\section{3 潜在生态廊道识别}

\subsection{1 核心生境斑块(源)的划定}

利用生境适宜性指数表征马可波罗盘羊的生 境需求与其分布环境之间的关系 (诸暮海锦等, 2014)。计算公式如下:

$$
\mathrm{HSI}=\left(\prod F_{i}\right)^{\frac{1}{n}}
$$

式中, $F_{i}$ 代表每个因子对马可波罗盘羊的适宜性取
值(表1)，适宜性得分依据野外采集的马可波罗盘羊 分布点数据(164个位点), 以及前人的研究结果, 并 结合专家打分法确定。 $F_{i}$ 介于 $0-100 \%$ ，其值越高表 示生境适宜性越高。 $n$ 表示生境因子个数, 此处 $n=$ 6。为避免因子之间可能高度自相关而干扰模型分 析结果，本文运用ArcGIS中的“波段集统计”空间分 析工具, 对6种生境因子进行了相关性分析, 结果 表明各因子间相关系数均小于 0.5 , 不存在相关性。

仅考虑自然因素的理想条件下，获得的是野生 动物的潜在生境, 但潜在生境往往受多种因素干扰 而无法被野生动物有效利用，因此不能客观反映出 野生动物的实际生境状况。基于此, 本文选用距国 道314线距离、距乡道距离、距居民点距离以及距 牧场距离为主要人为干扰因子(表1), 修正马可波罗 盘羊的潜在生境而获得实际生境。

采用ArcGIS中自带的Natural Breaks方法将所 得的HSI划分为不适宜生境、一般生境、较适宜生 境、最适宜生境4个等级。HSI模型建立后，利用2018 年从野外调查的马可波罗盘羊位点、粪便等夏冬两 季分布点数据(81、50)验证适宜性分析结果的准确 度(王志强等, 2009; 刘慧明等, 2016)。参照前人在 塔吉克斯坦对马可波罗盘羊的研究以及专家意见， 夏季约 $10 \mathrm{~km}^{2}$ 的最适宜生境面积能够维持大约 20 只 马可波罗盘羊个体; 冬季20只个体的集群至少需要 约 $5 \mathrm{~km}^{2}$ 的面积(Yeganeh et al, 2016)。本文将夏季最 适宜生境中面积 $>10 \mathrm{~km}^{2}$ 的生境斑块作为核心生境 斑块(core patches, CPs); 将冬季最适宜生境中面 积 $>5 \mathrm{~km}^{2}$ 的斑块作为核心生境斑块。

\subsection{2 阻力栅格构建}

根据生境适宜性指数的结果设置阻力值(李维 平等, 2017), 设定最高阻力为 100 , 最低为 1 。此外 依 据马可波罗盘羊对生境的实际需求, 参考前人的研 究结果，以及人类活动干扰强度(王玉涛等，2016; Salas et al, 2017), 在ArcGIS中将各因子统一设定4 个适宜性级别并分别赋阻力值：最适宜生境(1)、较 适宜生境(30)、一般生境(60)和不适宜生境(100)。 阻力图层的每一个值反映的是当物种经过该栅格 时遇到的阻碍, 阻力值越大, 说明阻碍越强, 迁移 成本越高。

\subsection{3 廊道质量及其与核心生境斑块的重要性分析}

将上述所得马可波罗盘羊核心生境斑块和计 算所得的阻力图层共同导入Linkage Mapper廊道模 
表1影响马可波罗盘羊的生境因子取值 $\left(F_{i}\right)$

Table 1 Values of habitat factors of Marco Polo sheep

\begin{tabular}{|c|c|c|c|c|c|c|}
\hline \multirow{2}{*}{$\begin{array}{l}\text { 生境因子 } \\
\text { Habitat factors }\end{array}$} & \multirow{2}{*}{$\begin{array}{l}\text { 范围 } \\
\text { Range }\end{array}$} & \multicolumn{2}{|c|}{$F_{i}(\%)$} & \multirow{2}{*}{$\begin{array}{l}\text { 生境因子 } \\
\text { Habitat factors }\end{array}$} & \multirow{2}{*}{$\begin{array}{l}\text { 范围 } \\
\text { Range }\end{array}$} & \multirow{2}{*}{$\begin{array}{l}F_{i} \\
(\%)\end{array}$} \\
\hline & & 夏季 & 冬季 Winter & & & \\
\hline \multirow{5}{*}{$\begin{array}{l}\text { 海拔 } \\
\text { Elevation (m) }\end{array}$} & $\leq 3,500$ & 2 & 0 & \multirow{5}{*}{$\begin{array}{l}\text { 距国道314线距离 } \\
\text { Distance to G314 national } \\
\text { road (m) }\end{array}$} & $\leq 1,000$ & 0 \\
\hline & $3,501-4,000$ & 65 & 65 & & $1,001-2,000$ & 25 \\
\hline & $4,001-4,500$ & 100 & 100 & & $2,001-3,000$ & 50 \\
\hline & $4,501-5,000$ & 10 & 14 & & $3,001-4,000$ & 75 \\
\hline & $\geq 5,001$ & 5 & 0 & & $\geq 4,001$ & 100 \\
\hline \multirow{4}{*}{$\begin{array}{l}\text { 坡度 } \\
\text { Slope }\left(^{\circ}\right)\end{array}$} & $\leq 10$ & 35 & 100 & \multirow{5}{*}{$\begin{array}{l}\text { 距乡道距离 } \\
\text { Distance to village road (m) }\end{array}$} & $\leq 400$ & 0 \\
\hline & $11-20$ & 100 & 83 & & $401-600$ & 25 \\
\hline & $21-30$ & 40 & 44 & & $601-800$ & 50 \\
\hline & $\geq 31$ & 30 & 35 & & $801-1,000$ & 75 \\
\hline \multirow{3}{*}{$\begin{array}{l}\text { 坡位 } \\
\text { Slope position }\end{array}$} & 上 Top & 60 & 69 & & $\geq 1,001$ & 100 \\
\hline & 中 Middle & 100 & 100 & \multirow{5}{*}{$\begin{array}{l}\text { 距居民点距离 } \\
\text { Distance to settlement (m) }\end{array}$} & $\leq 400$ & 0 \\
\hline & 下 Bottom & 40 & 63 & & $401-800$ & 25 \\
\hline \multirow{4}{*}{$\begin{array}{l}\text { 坡向 } \\
\text { Slope aspect }\end{array}$} & 东 East & 100 & 73 & & $801-1,200$ & 50 \\
\hline & 南 South & 60 & 100 & & $1,201-1,600$ & 75 \\
\hline & 西 West & 35 & 16 & & $\geq 1,601$ & 100 \\
\hline & 北 North & 65 & 50 & \multirow{11}{*}{$\begin{array}{l}\text { 距牧场距离 } \\
\text { Distance to pastures (m) }\end{array}$} & $\leq 750$ & 0 \\
\hline \multirow{7}{*}{$\begin{array}{l}\text { 植被类型 } \\
\text { Vegetation type }\end{array}$} & 垫状驼线藜高寒荒漠 ${ }^{a}$ & 5 & 0 & & $751-1,500$ & 25 \\
\hline & 风毛菊、红景天稀疏植被 ${ }^{\mathrm{b}}$ & 10 & 0 & & $1,501-2,250$ & 50 \\
\hline & 羊茅高寒草原 & 20 & 22 & & $2,251-3,000$ & 75 \\
\hline & 短花针茅荒漠草原 ${ }^{\mathrm{d}}$ & 25 & 30 & & $\geq 3,001$ & 100 \\
\hline & 麻黄荒漠e & 30 & 17 & & & \\
\hline & 驼线藜荒漠 ${ }^{\mathrm{f}}$ & 45 & 17 & & & \\
\hline & $\begin{array}{l}\text { 高山绢蒿、高山紫菀高寒荒 } \\
\text { 漠g }\end{array}$ & $\mathrm{t}_{100}$ & 100 & & & \\
\hline \multirow{3}{*}{$\begin{array}{l}\text { 距水源距离 } \\
\text { Distance to water (m) }\end{array}$} & $\leq 1,000$ & 100 & 100 & & & \\
\hline & $1,001-2,000$ & 65 & 48 & & & \\
\hline & $\geq 2,001$ & 55 & 63 & & & \\
\hline
\end{tabular}

a, Ceratoides compacta alpine desert; b, Saussurea spp.+ Rhodiola spp. sparse vegetation; c, Festuca spp. alpine grassland; d, Stipa breviflora desert steppe; e, Ephedra spp. desert; f, Ceratoides latens desert; g, Seriphidium rhodanthum + Aster alpinus alpine desert.

拟软件, 识别并分析马可波罗盘羊的潜在廊道。

运用两种不同的度量方法描述每条廊道的质

量(Dutta et al, 2016)。第一种是基于每一对相邻核心 生境斑块间廊道的成本加权距离与欧几里得距离 (Euclidean Distance, EucD)的比值(CWD : EucD)。比 值越大, 意味着该廊道的阻力也越大。对于具有最 高质量的廊道其成本加权距离等于欧几里得距离, 因此比值为 1 。这一比值表示相对于相邻核心生境 斑块间的距离, 盘羊在两者之间移动的困难程度。 第二种是利用成本加权距离与最小成本路径的比 值(CWD：LCP), 该比值反映出个体在一对相邻的 核心生境斑块之间迁移时, 在所选择的最佳路径上
遇到的平均阻力。

廊道绘制完成后, 运行 Centrality Mapper (McRae, 2012)模块调用电路理论程序Circuitscape (McRae \& Shah, 2009)估算每个生境斑块与廊道的 中心性值。中心性值表示每个核心生境斑块和走廊 在维护整个生境斑块网络连通性的重要性, 值越高, 重要性越高(Carroll et al, 2012)。

\section{3 结果}

\section{1 马可波罗盘羊适宜生境与核心生境斑块}

依据生境适宜性指数模型计算结果可知(图2), 马可波罗盘羊的一般适宜生境、较适宜生境与最适 

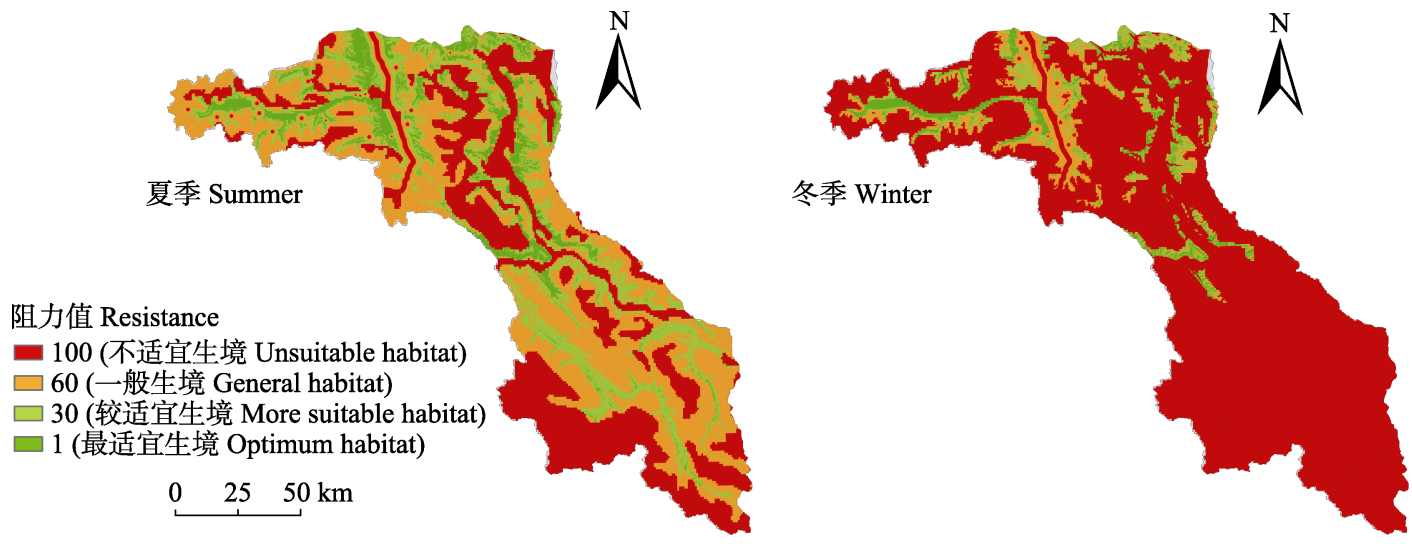

图2 马可波罗盘羊栖息地阻力(适宜性等级)栅格图

Fig. 2 Grid in resistance (habitat suitability) of Marco Polo sheep' habitat

宜生境主要分布于保护区西北部。夏季三者的面积 分别为5,988.44 $\mathrm{km}^{2} 、 3,191.72 \mathrm{~km}^{2} 、 1,268.76 \mathrm{~km}^{2}$, 合 计 $10,436.92 \mathrm{~km}^{2}$, 占保护区总面积的 $65.79 \%$; 冬季 三者的面积分别为 $1,193.95 \mathrm{~km}^{2} 、 1,005.41 \mathrm{~km}^{2}$ 、 $652.33 \mathrm{~km}^{2}$, 合计 $2,851.69 \mathrm{~km}^{2}$, 占保护区总面积的 $17.97 \%$ 。夏季适宜生境总面积显著高于冬季(图2)。

保护区西北部是马可波罗盘羊核心生境斑块分 布最集中且面积相对较大的区域。夏冬两季马可波 罗盘羊核心生境斑块较少, 均为28 (图3), 总面积分 别为 $1,075.42 \mathrm{~km}^{2}$ 和 $454.66 \mathrm{~km}^{2}$, 占整个保护区面积 的6.78\%和 $2.87 \%$ 。适宜性分析的准确度验证结果表 明, 夏冬两季分别有 $93.62 \% 、 76 \%$ 的盘羊分布点落在 适宜生境内, 表明生境适宜性评价结果比较准确。

\section{2 核心生境斑块间的潜在生态廊道质量}

夏季连接 28 个核心生境斑块的潜在廊道有 45 条, 冬季有 47 条(图3), 总长度分别为 $417.55 \mathrm{~km}$ 和 $701.36 \mathrm{~km}$, 廊道平均长度分别为 $9.28 \mathrm{~km}$ 和 14.92 $\mathrm{km}$ 。廊道大多集中在保护区西北部, 且长度大多小 于 $9 \mathrm{~km}$ 。多数核心生境斑块间有数条廊道连接, 例 如在夏季斑块4-6、19-20间分别有3条及3条以上可 供盘羊移动的廊道(图4)。

夏季 45 条廊道的欧几里得距离平均值为 20.87 $\pm 10.40 \mathrm{~km}$ (5.93-53.19 km), 加权成本距离平均值 为299.72 $\pm 23.67 \mathrm{~km}(9.60-1,056.31 \mathrm{~km})$, 最小成本 路径平均值为 $9.28 \pm 6.44 \mathrm{~km}(0.90-30.62 \mathrm{~km})($ 表 2$)$ 。 夏季廊道中, 欧几里得距离、最小成本路径及加权 平均距离最小的3条廊道是5-10、6-9和3-28斑块间, 最大的是14-24和17-20斑块间。冬季47条廊道的欧 几里得距离平均值为20.72 $\pm 11.26 \mathrm{~km}(4.22-48.11$ $\mathrm{km})$, 加权成本距离平均值为726.63 $\pm 599.11 \mathrm{~km}$ (28.32-2,136.49 km), 最小成本路径平均值为14.92 $\pm 10.49 \mathrm{~km}(2.22-41.54 \mathrm{~km})$ (表3)。冬季欧几里得距 离、最小成本路径及加权平均距离最小的 3 条廊道 是 12-18、6-9和 9-12 斑块间, 最大的是 17-20、 19-25、20-19和20-24斑块间。

从加权平均距离与欧几里得距离的比值 (CWD：EucD)来分析, 夏季 45 条廊道的平均值为 $15.12 \pm 9.72$ 。比值最低的廊道是3-28、17-20、4-20 和1-3斑块间, 表明这4条廊道质量较高, 盘羊在其 中迁移的成本较低; 而比值较高的廊道是10-11、 1-11、10-12斑块间, 这3条廊道质量较低, 盘羊在 其中迁移的成本较高(表2)。冬季47条廊道的平均值 为32.87 \pm 18.20 。其中比值较低的廊道是 $17-20$ 、 3-15和17-22斑块间, 廊道质量较高; 比值较高的 廊道是23-24和19-24, 表明盘羊在其中迁移的成本 较高(表3)。夏季廊道中, 7-28 (EucD = 12.60)和 18-19 (EucD = 12.59) 的欧几里得距离几乎相等, 但 是在7-28中迁移消耗的成本(CWD : EucD = 15.68) 要比18-19 (5.71)大很多(表2)。

从加权成本距离与最小成本路径的比值 (CWD：LCP)来分析, 夏季45条廊道的平均值为 $32.82 \pm 17.07$ 。其中比值较低的廊道是 $1-3$ 和3-28, 表明这 2 条廊道质量较高, 盘羊在其中迁移的成本 较低。比值较高的廊道是10-11、15-23和14-15, 表 明盘羊在其中迁移的成本较高。以夏季廊道10-14 和7-9为例，二者最小成本路径基本相同(分别为 $7.37 \mathrm{~km}$ 和7.47 km), 盘羊沿最低成本路径移动时, 在10-14所遇到的平均阻力要比7-9 小很多(CWD： 

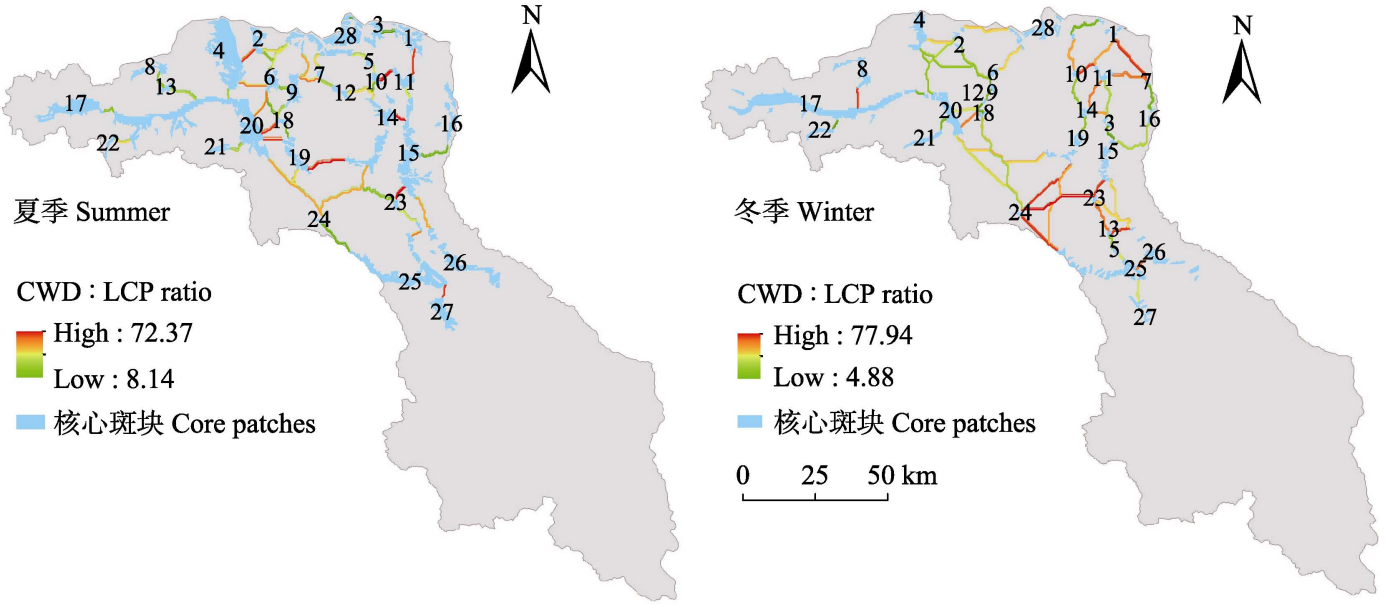

\begin{tabular}{rl||cl}
\hline & \multicolumn{1}{c||}{ 地名 Name } & \multicolumn{1}{c}{ 地名 Name } \\
\hline 1 & 哈尔努孜 Haernuzi & 15 & 可莫达坂 Kemodaban \\
2 & 沙依地库 Shayidiku & 16 & 萨提曼 Satiman \\
3 & 同库 Tongku & 17 & 科克吐鲁克 Keketuluke \\
4 & 皮斯岭 Pisiling & 18 & 依西代尔 Yixidaier \\
5 & 马拉特 Malate & 19 & 喀拉苏 Kalasu \\
6 & 赞坎 Zankan & 20 & 帕日帕克 Paripake \\
7 & 也尔赫特 Yeerhete & 21 & 打吾拉克 Dawulake \\
8 & 排依克 Paiyike & 22 & 明铁盖 Mingtiegai \\
9 & 沙尔比列 Shaerbilie & 23 & 千里克库 Qianlikeku \\
10 & 其克尔克尔 Qikeerkeer & 24 & 铁干里克 Tieganlike \\
11 & 亚希洛夫 Yaxiluofu & 25 & 色克布拉克 Sekebulake \\
12 & 古木喀克 Gumukake & 26 & 穷托卡依 Qiongtuokayi \\
13 & 恰恩阿勒 Qiaenale & 27 & 塔吐鲁 Tatulu \\
14 & 库塔孜 Kutazi & 28 & 马尔洋 Maeryang \\
& & & \\
\hline
\end{tabular}

\begin{tabular}{rl||rl}
\hline \multicolumn{1}{c||}{ 地名 Name } & \multicolumn{2}{c}{ 地名 Name } \\
\hline 1 & 哈尔努孜 Haernuzi & 15 & 塔萨拉 Tasala \\
2 & 沙依地库 Shayidiku & 16 & 萨提曼 Satiman \\
3 & 爱勒米希 Ailemixi & 17 & 科克吐鲁克 Keketuluke \\
4 & 阔克加尔 Kuokejiaer & 18 & 依西代尔 Yixidaier \\
5 & 热斯喀木 Resikamu & 19 & 卡大肯 Kadaken \\
6 & 铁尔布尔列 Tieerbuerlie & 20 & 帕日帕克 Paripake \\
7 & 哈拉巴吐 Halabatu & 21 & 打吾拉克 Dawulake \\
8 & 排依克 Paiyike & 22 & 群沙拉 Qunshala \\
9 & 沙尔比列 Shaerbilie & 23 & 千里克库 Qianlikeku \\
10 & 其克尔克尔 Qikeerkeer & 24 & 铁干里克 Tieganlike \\
11 & 亚希洛夫 Yaxiluofu & 25 & 色克布拉克 Sekebulake \\
12 & 沙尔比列西南 & 26 & 穷托卡依 Qiongtuokayi \\
& Southwest Shaerbilie & 27 & 塔吐鲁 Tatulu \\
13 & 乌如克 Wuruke & 28 & 马尔洋 Maeryang \\
14 & 多扎克 Duozhake & & \\
\hline
\end{tabular}

图3 马可波罗盘羊核心生境斑块及成本加权距离(CWD)与最小成本路径(LCP)之比所示的廊道质量。红色表示沿着最小成 本路径移动的成本较高, 绿色表示在最小成本路径上连接的质量更高。图中数字代表核心生境斑块。

Fig. 3 Core habitat areas of Marco Polo sheep and the quality of linkages shown by the ratio of cost-weighted distance (CWD) to least-cost path (LCP). Red lines indicate higher cost of movement along the path of least resistance and green lines indicate higher quality along the least-cost path. The numbers in the figure represent core patches.

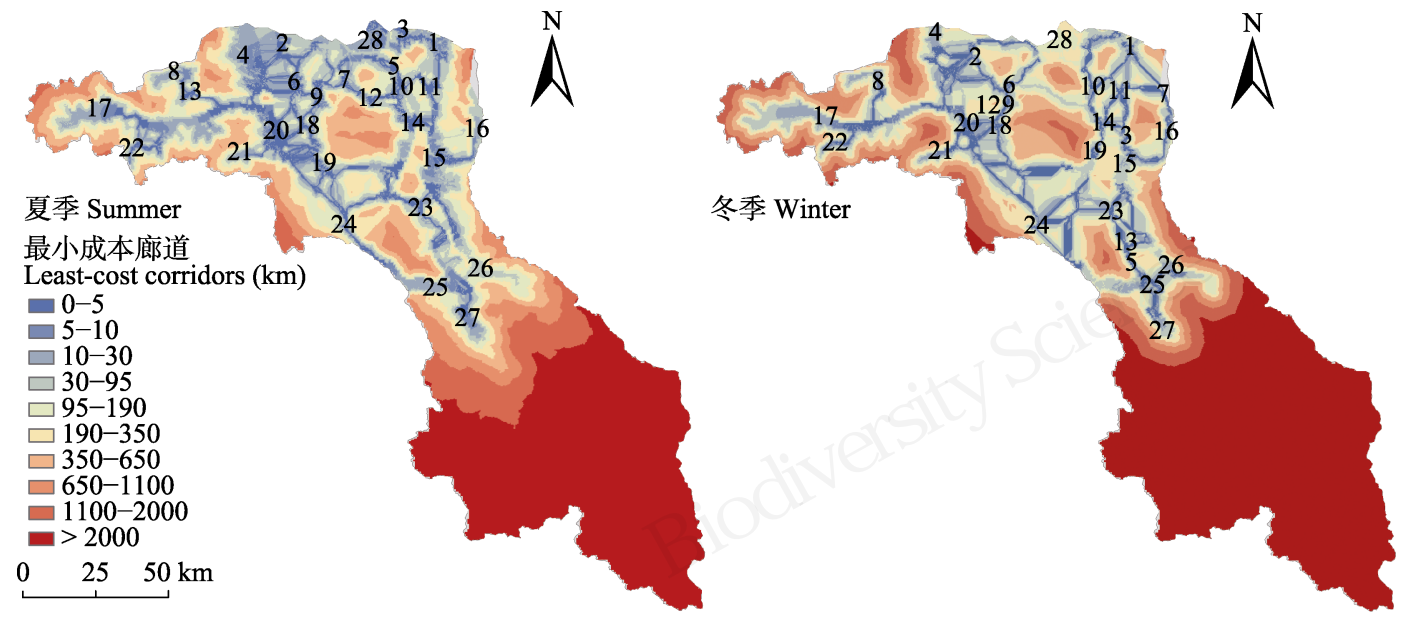

图4 马可波罗盘羊的最小成本廊道分布图。蓝色区域表示阻力较低的路径, 红色区域表示成本加权距离非常大。数字含义 同图3。

Fig. 4 Maps showing least-cost corridors for the Marco polo sheep in the study area. Lower resistance paths are shown in blue, and red areas represent higher cost-weighted distance. 
表2 夏季28个核心生境斑块(CPs)之间45条廊道的特征

Table 2 Characteristics of the 45 mapped corridors between the 28 core patches in the summer

\begin{tabular}{|c|c|c|c|c|c|c|c|c|c|c|c|c|c|}
\hline $\begin{array}{l}\text { 廊道 } \\
\text { Corridor }\end{array}$ & $\begin{array}{l}\text { 欧几里 } \\
\text { 得距离 } \\
\text { EucD } \\
(\mathrm{km})\end{array}$ & $\begin{array}{l}\text { 加权成 } \\
\text { 本距离 } \\
\text { CWD } \\
(\mathrm{km})\end{array}$ & $\begin{array}{l}\text { 最小成 } \\
\text { 本路径 } \\
\text { LCP } \\
(\mathrm{km})\end{array}$ & $\begin{array}{l}\text { CWD : } \\
\text { EucD }\end{array}$ & $\begin{array}{l}\text { CWD : } \\
\text { LCP }\end{array}$ & $\begin{array}{l}\text { 中心 } \\
\text { 性值 } \\
\text { CFC } \\
\text { (Amps) }\end{array}$ & \begin{tabular}{|l} 
廊道 \\
Corridor
\end{tabular} & $\begin{array}{l}\text { 欧几里 } \\
\text { 得距离 } \\
\text { EucD } \\
(\mathrm{km})\end{array}$ & $\begin{array}{l}\text { 加权成本 } \\
\text { 距离 } \\
\text { CWD } \\
(\mathrm{km})\end{array}$ & $\begin{array}{l}\text { 最小成本 } \\
\text { 路径 } \\
\text { LCP } \\
(\mathrm{km})\end{array}$ & $\begin{array}{l}\text { CWD : } \\
\text { EucD }\end{array}$ & $\begin{array}{l}\text { CWD : } \\
\text { LCP }\end{array}$ & $\begin{array}{l}\text { 中心 } \\
\text { 性值 } \\
\text { CFC } \\
\text { (Amps) }\end{array}$ \\
\hline $3-28$ & 13.68 & 9.60 & 0.90 & 0.70 & 10.67 & 75.06 & $19-20$ & 33.96 & 378.30 & 6.30 & 11.14 & 60.05 & 35.23 \\
\hline $5-10$ & 5.93 & 59.95 & 2.35 & 10.12 & 25.53 & 69.68 & 9-28 & 21.94 & 345.53 & 10.56 & 15.75 & 32.71 & 34.34 \\
\hline $4-20$ & 25.24 & 65.65 & 2.95 & 2.60 & 22.27 & 68.02 & |7-28 & 12.60 & 197.59 & 6.77 & 15.68 & 29.20 & 33.65 \\
\hline $5-28$ & 14.41 & 151.92 & 5.55 & 10.55 & 27.40 & 67.89 & |20-24 & 53.19 & $1,024.50$ & 28.79 & 19.26 & 35.59 & 32.74 \\
\hline $25-26$ & 19.42 & 150.66 & 3.62 & 7.76 & 41.61 & 66.95 & $14-23$ & 24.48 & 457.02 & 23.16 & 18.67 & 19.74 & 32.55 \\
\hline $24-25$ & 34.96 & 239.04 & 15.21 & 6.84 & 15.72 & 62.88 & $18-20$ & 27.22 & 389.17 & 6.59 & 14.30 & 59.05 & 32.32 \\
\hline $11-15$ & 26.88 & 118.06 & 4.35 & 4.39 & 27.17 & 59.10 & |6-20 & 27.56 & 424.47 & 10.39 & 15.40 & 40.86 & 32.26 \\
\hline $10-14$ & 19.88 & 109.08 & 7.37 & 5.49 & 14.81 & 56.77 & $12-14$ & 20.13 & 391.45 & 13.74 & 19.45 & 28.49 & 31.20 \\
\hline $1-3$ & 13.30 & 39.67 & 4.87 & 2.98 & 8.14 & 56.26 & |15-23 & 17.21 & 380.47 & 5.32 & 22.10 & 71.54 & 29.35 \\
\hline $18-19$ & 12.59 & 71.92 & 4.87 & 5.71 & 14.76 & 53.08 & $10-11$ & 9.67 & 402.79 & 5.57 & 41.64 & 72.37 & 28.81 \\
\hline $13-20$ & 16.96 & 222.02 & 10.49 & 13.09 & 21.16 & 52.00 & $4-6$ & 18.49 & 407.77 & 9.67 & 22.05 & 42.16 & 27.89 \\
\hline $7-12$ & 9.33 & 128.15 & 5.37 & 13.74 & 23.87 & 51.24 & $8-13$ & 8.31 & 113.96 & 6.39 & 13.72 & 17.82 & 27.00 \\
\hline $6-9$ & 8.20 & 66.22 & 3.37 & 8.08 & 19.64 & 49.61 & |15-16 & 20.48 & 187.68 & 12.66 & 9.16 & 14.82 & 27.00 \\
\hline $9-18$ & 11.71 & 126.48 & 5.19 & 10.81 & 24.35 & 46.89 & $17-20$ & 44.94 & 79.65 & 4.65 & 1.77 & 17.15 & 27.00 \\
\hline $2-28$ & 26.20 & 301.39 & 10.17 & 11.50 & 29.64 & 44.66 & |20-21 & 11.31 & 125.54 & 5.67 & 11.10 & 22.14 & 27.00 \\
\hline $23-26$ & 30.33 & 214.05 & 8.39 & 7.06 & 25.51 & 43.61 & $20-22$ & 33.10 & 174.76 & 5.85 & 5.28 & 29.90 & 27.00 \\
\hline 7-9 & 10.44 & 304.11 & 7.47 & 29.14 & 40.72 & 42.75 & |25-27 & 19.13 & 240.98 & 4.57 & 12.60 & 52.71 & 27.00 \\
\hline $14-15$ & 13.17 & 282.16 & 4.05 & 21.42 & 69.76 & 40.14 & 14-19 & 29.39 & 895.98 & 13.97 & 30.49 & 64.15 & 26.42 \\
\hline $1-11$ & 14.26 & 507.33 & 9.32 & 35.58 & 54.43 & 38.09 & $2-6$ & 14.56 & 172.00 & 9.06 & 11.81 & 18.98 & 26.31 \\
\hline $6-28$ & 25.55 & 347.54 & 13.21 & 13.60 & 26.30 & 38.01 & |6-18 & 14.43 & 187.94 & 11.52 & 13.03 & 16.32 & 26.30 \\
\hline $19-24$ & 24.20 & 663.07 & 22.25 & 27.39 & 29.81 & 36.52 & |10-12 & 13.10 & 451.88 & 14.46 & 34.50 & 31.24 & 21.91 \\
\hline $15-26$ & 40.58 & 457.27 & 13.74 & 11.27 & 33.28 & 35.96 & $14-24$ & 35.42 & $1,056.31$ & 30.62 & 29.82 & 34.49 & 19.06 \\
\hline $2-4$ & 11.42 & 366.32 & 6.24 & 32.07 & 58.71 & 35.74 & $\begin{array}{l}\text { 平均 } \\
\text { Average }\end{array}$ & 20.54 & 282.52 & 8.79 & 14.79 & 32.78 & 41.00 \\
\hline
\end{tabular}

廊道一列中数字代表的地名同图3, 例如3-28表示核心斑块3和28之间的廊道。

The names of location represented by numbers in the column of corridors are the same as Fig. 3. CWD, Cost-weighted distance; EucD, Euclidean distance; LCP, Least-cost path; CFC, Current flow centrality.

LCP比值分别为 14.81 和 40.72 , 表2)。冬季 47 条廊道 的CWD：LCP平均值为 $45.45 \pm 20.66$, 比值较低的 廊道是3-15和12-18, 表示这2条廊道质量较高。而 比值较高的2条廊道是23-24和19-24, 表明盘羊在 其中迁移的成本较高(表3，图4)。

夏季多数廊道的CWD : LCP值较低, 而冬季多 数廊道的CWD：LCP值较高, 但冬夏两季国道314 线两侧的马可波罗盘羊生境斑块间廊道的移动成 本均比较高, 而且冬季的廊道质量普遍更低(表2, 表3)。

\section{3 核心生境斑块与廊道的中心性值}

夏季的核心生境斑块中, 20 和28的中心性值最 高, 其次是6、9和14, 而处于研究区边缘地带的斑
块8、16、17、21和27的中心性值均很低(图5)。冬 季20、15、28这三个核心生境斑块中心性值最高，其 次是6和 14 , 同样处于边缘地带的4、8、22、21和 27 这几个核心生境斑块的中心性值均很低(图5)。这一 结果表明夏季20、28、6和冬季20、15、28是维持 马可波罗盘羊核心生境之间相互联系的重要斑块。 相应的, 冬夏各廊道的中心性值也显示斑块20在整 个区域网络连接中占据重要地位。

夏季廊道中, 3-28、5-10和4-20这3条廊道的中 心性值较高；14-24和10-12这2条廊道的中心性值 较低(表2, 图5)。冬季廊道中, 3-15、9-12和6-9的中 心性值较高，而廊道19-24和4-6的中心性值较低 (表3，图5)。 
表3 冬季28个核心生境斑块(CPs)之间47条廊道的特征

Table 3 Characteristics of the 47 mapped corridors between the 28 core patches in winter

\begin{tabular}{|c|c|c|c|c|c|c|c|c|c|c|c|c|c|}
\hline $\begin{array}{l}\text { 廊道 } \\
\text { Corridor }\end{array}$ & $\begin{array}{l}\text { 欧几里 } \\
\text { 得距离 } \\
\text { EucD } \\
(\mathrm{km})\end{array}$ & $\begin{array}{l}\text { 加权成 } \\
\text { 本距离 } \\
\text { CWD } \\
(\mathrm{km})\end{array}$ & $\begin{array}{l}\text { 最小成 } \\
\text { 本距离 } \\
\text { LCP } \\
(\mathrm{km})\end{array}$ & $\begin{array}{l}\text { CWD : } \\
\text { EucD }\end{array}$ & $\begin{array}{l}\text { CWD : } \\
\text { LCP }\end{array}$ & $\begin{array}{l}\text { 中心 } \\
\text { 性值 } \\
\text { CFC } \\
\text { (Amps) }\end{array}$ & \begin{tabular}{|l} 
廊道 \\
Corridor
\end{tabular} & $\begin{array}{l}\text { 欧几里 } \\
\text { 得距离 } \\
\text { EucD } \\
(\mathrm{km})\end{array}$ & $\begin{array}{l}\text { 加权成 } \\
\text { 本距离 } \\
\text { CWD } \\
(\mathrm{km})\end{array}$ & $\begin{array}{l}\text { 最小成 } \\
\text { 本距离 } \\
\text { LCP } \\
(\mathrm{km})\end{array}$ & $\begin{array}{l}\text { CWD : } \\
\text { EucD }\end{array}$ & $\begin{array}{l}\text { CWD : } \\
\text { LCP }\end{array}$ & $\begin{array}{l}\text { 中心 } \\
\text { 性值 } \\
\text { CFC } \\
\text { (Amps) }\end{array}$ \\
\hline $3-15$ & 13.49 & 30.95 & 6.34 & 2.29 & 4.88 & 91.46 & $25-26$ & 20.05 & 412.09 & 6.17 & 20.55 & 66.83 & 36.05 \\
\hline $9-12$ & 5.48 & 88.06 & 4.05 & 16.08 & 21.77 & 80.38 & $18-24$ & 36.71 & $1,636.84$ & 41.54 & 44.59 & 39.40 & 34.71 \\
\hline $6-9$ & 5.48 & 28.32 & 2.22 & 5.17 & 12.74 & 79.90 & $23-13$ & 12.86 & 803.84 & 11.82 & 62.49 & 68.04 & 34.00 \\
\hline $17-20$ & 48.11 & 45.08 & 3.07 & 0.94 & 14.67 & 75.00 & $4-20$ & 30.13 & 593.00 & 18.69 & 19.68 & 31.74 & 33.77 \\
\hline $1-28$ & 24.28 & 195.34 & 13.51 & 8.04 & 14.46 & 73.43 & 20-19 & 43.16 & $2,051.04$ & 38.53 & 47.53 & 53.24 & 31.33 \\
\hline $14-19$ & 14.25 & 183.03 & 7.37 & 12.84 & 24.85 & 71.63 & $18-19$ & 31.93 & $1,837.59$ & 37.42 & 57.54 & 49.10 & 30.64 \\
\hline $12-18$ & 4.22 & 45.40 & 5.19 & 10.76 & 8.74 & 65.19 & $1-7$ & 21.97 & $1,361.46$ & 19.17 & 61.96 & 71.01 & 30.56 \\
\hline $6-28$ & 21.66 & 619.93 & 12.31 & 28.62 & 50.35 & 63.12 & $11-10$ & 9.71 & 518.61 & 7.32 & 53.43 & 70.90 & 27.77 \\
\hline $15-23$ & 13.68 & 480.66 & 6.64 & 35.14 & 72.37 & 61.96 & $8-17$ & 20.23 & 499.82 & 6.85 & 24.71 & 72.99 & 27.00 \\
\hline $14-3$ & 8.23 & 355.53 & 6.02 & 43.20 & 59.05 & 59.63 & $17-22$ & 10.07 & 41.90 & 3.50 & 4.16 & 11.98 & 27.00 \\
\hline $5-25$ & 6.81 & 111.03 & 2.42 & 16.31 & 45.86 & 53.14 & $20-21$ & 12.28 & 97.28 & 4.57 & 7.92 & 21.28 & 27.00 \\
\hline $13-5$ & 6.66 & 154.23 & 5.72 & 23.14 & 26.96 & 47.54 & $25-27$ & 17.96 & 377.52 & 8.07 & 21.03 & 46.79 & 27.00 \\
\hline $24-25$ & 35.90 & $1,235.26$ & 17.20 & 34.41 & 71.83 & 46.03 & $19-25$ & 43.78 & 2,136.49 & 35.55 & 48.80 & 60.10 & 26.56 \\
\hline $2-28$ & 28.36 & 858.78 & 16.54 & 30.29 & 51.91 & 45.31 & $2-4$ & 13.89 & 570.71 & 11.37 & 41.08 & 50.20 & 26.53 \\
\hline $10-28$ & 18.74 & 711.69 & 12.36 & 37.98 & 57.57 & 44.83 & $2-6$ & 16.72 & 557.02 & 17.43 & 33.31 & 31.95 & 24.45 \\
\hline $7-16$ & 11.57 & 179.77 & 12.06 & 15.54 & 14.90 & 44.40 & $2-20$ & 25.92 & $1,015.82$ & 25.60 & 39.18 & 39.69 & 23.94 \\
\hline $16-15$ & 21.83 & 686.87 & 19.66 & 31.47 & 34.94 & 43.52 & $11-7$ & 15.35 & 914.29 & 13.97 & 59.57 & 65.47 & 23.56 \\
\hline $11-3$ & 16.52 & 529.36 & 15.44 & 32.04 & 34.29 & 43.31 & $13-26$ & 20.94 & 503.17 & 7.05 & 24.02 & 71.42 & 22.93 \\
\hline $10-14$ & 13.56 & 379.56 & 13.02 & 28.00 & 29.16 & 41.61 & $23-24$ & 26.53 & 2,109.18 & 27.06 & 79.51 & 77.94 & 22.45 \\
\hline $1-11$ & 15.50 & 700.52 & 12.51 & 45.20 & 56.00 & 40.67 & $23-26$ & 31.65 & 987.18 & 19.18 & 31.19 & 51.46 & 22.23 \\
\hline 20-12 & 12.83 & 508.98 & 11.14 & 39.68 & 45.68 & 38.35 & $11-14$ & 14.05 & 740.74 & 11.41 & 52.71 & 64.91 & 20.86 \\
\hline 20-18 & 11.71 & 507.04 & 7.99 & 43.30 & 63.47 & 37.17 & $4-6$ & 29.28 & 955.24 & 30.68 & 32.62 & 31.14 & 18.96 \\
\hline $15-26$ & 39.21 & $1,204.82$ & 23.79 & 30.73 & 50.65 & 36.48 & $19-24$ & 28.16 & $1,815.86$ & 24.56 & 64.49 & 73.92 & 17.89 \\
\hline $20-24$ & 42.64 & $1,774.72$ & 37.30 & 41.62 & 47.58 & 36.14 & $\begin{array}{l}\text { 平均 } \\
\text { Average }\end{array}$ & 20.72 & 726.63 & 14.92 & 32.87 & 45.45 & 41.22 \\
\hline
\end{tabular}

廊道一列中数字代表的地名同图3。

The names of location represented by numbers in the column of corridors are the same as Fig. 3. CWD, Cost-weighted distance; EucD, Euclidean distance; LCP, Least-cost path; CFC, Current flow centrality.

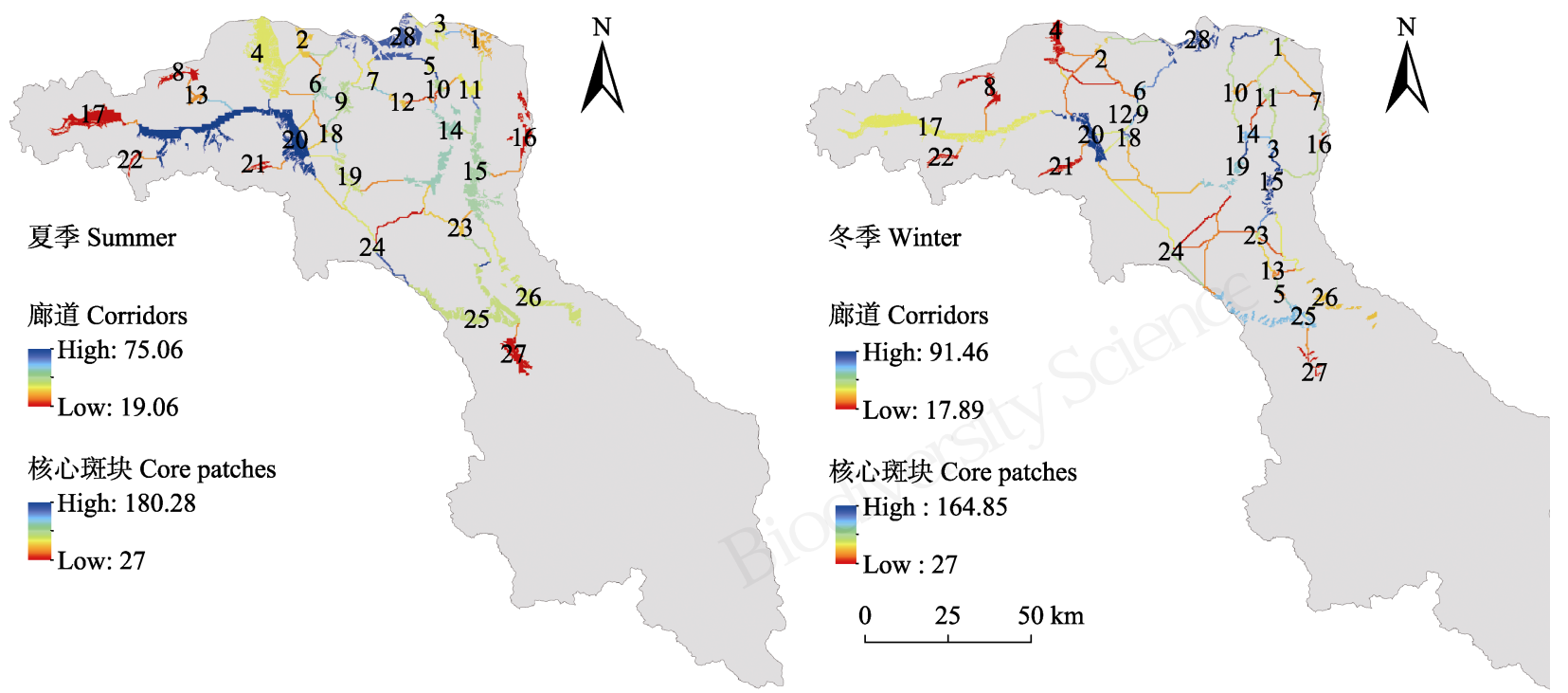

图5 研究区域核心生境斑块(CPs)和各廊道中心性值(色块显示的数值)

Fig. 5 Current centrality for core patches (CPs) and corridors in the study area 


\section{4 讨论}

\section{1 核心生境的地理分布特征}

本文的研究结果表明, 夏、冬两季马可波罗盘 羊适宜生境主要集中分布于保护区西北部及中部 较小的区域范围内，且核心生境斑块较分散，破碎 化较严重，在保护区东部几乎没有适宜生境分布 (图2)。Salas等(2017)研究发现马可波罗盘羊偏好坡 度较缓的开阔峡谷, 而保护区的西北部和中部为开 阔的峡谷和相对平缓的台地(图4)。冬季马可波罗盘 羊的适宜生境面积明显低于夏季，主要原因如下： (1)保护区冬季植被覆盖度明显低于夏季，植物枯萎， 加之积雪遮盖，地上可利用生物量远远低于夏季; (2)保护区冬季气候条件恶劣, 气温极低, 尤其是保 护区南部地形起伏, 山峰陡峭, 沟谷纵横, 气候条 件更加恶劣。而马可波罗盘羊对低温较敏感，所以 在冬季保护区东部大部分地区不适合其生存。Khan 等(2016)亦证实分布于中国和巴基斯坦交界处的马 可波罗盘羊在冬季主要选择植被覆盖度较高的区 域来躲避低温。

Schaller等(1987)曾于1959年在红其拉甫地区 记录过65只雄性马可波罗盘羊, 但是我们在近几年 野外调查中并未在此处发现马可波罗盘羊, 龚明吴 等(2007)也仅发现了盘羊的头骨。以此判断, 马可波 罗盘羊在保护区内的分布范围有向北退缩的趋势。 保护区位于帕米尔高原东缘，是马可波罗盘羊世界 分布区的最东南边缘地带。如果保护区生境持续恶 化, 人为干扰持续增加, 最终可能导致马可波罗盘 羊在中国境内消失。综上所述，保护区西北部是马 可波罗盘羊的重点保护区域, 应及时在该区域维持 和建立斑块之间的连通廊道, 以确保盘羊种群间的 基因交流，维持种群繁衍生存。

\section{2 核心生境斑块与廊道的中心性值}

夏季核心生境斑块 20 和 28 , 以及冬季核心生境 斑块20、15、28的中心性值最高, 因此应确保这些 斑块的连续性和完整性, 加强与周围其他景观类型 的连接, 以扩大斑块面积, 提高斑块质量, 促进马 可波罗盘羊的迁移和交流。夏季4-20、3-28和5-10, 以及冬季3-15、9-12和6-9这6条廊道的中心性值较 高, 这些廊道对于维持整个廊道网络的连通性最为 重要。此外, 这些廊道的最小成本距离相对较短, 极有可能是盘羊的迁移廊道。虽然上述廊道中心性
值很高，但就保护区整体而言，夏冬两季核心生境 斑块基本重叠，且大多数廊道沿沟谷分布，因此在 没有人为干扰和大型水体阻隔的情况下，廊道质量 主要与其最小成本路径上的欧几里得距离远近相 关。此外，根据CWD : EucD、CWD : LCP以及廊道 的中心性三个值得出，冬夏季共同的最优廊道是 17-20, 该廊道欧几里得距离短, 且连接着两个主 要的核心生境斑块, 因此在未来的保护工作中应重 点关注这些廊道和斑块。

马可波罗盘羊主要分布在中国与吉尔吉斯斯 坦、塔吉克斯坦、阿富汗和巴基斯坦等四国的边境 地带(Schaller \& Kang, 2008; Salas et al, 2017), 有季 节性迁徙的习性(Valdez et al, 2016)。保护区内马可 波罗盘羊种群的繁衍与发展主要依靠跨境基因交 流而维持。阿富汗境内的马可波罗盘羊主要集中于 瓦罕走廊(Smallwood et al, 2011), 已有研究表明在 保护区内中国瓦罕走廊区域的皮斯岭、卡拉奇古等 地存在马可波罗盘羊的跨境迁移廊道(Schaller \& Kang, 2008)。因此, 需要强调的是, 虽然本研究中 所识别的位于保护区边缘的生境斑块和廊道中心 性值较低，但并不意味着其重要性不足。原因如下： (1)夏季斑块8、17、21、22及冬季斑块8、22、21分 别位于中国与阿富汗和塔吉克斯坦边境沿线一带, 在维持马可波罗盘羊种群跨境基因交流方面起着 重要的桥梁作用。(2)虽然北部的1、2、4等斑块中 心性值也不高, 但它们是连接保护区内外种群基因 交流的桥梁。(3)虽然夏季斑块6、9、18、11和冬季 斑块10、9的面积较小, 中心性值较低, 但地理位置 重要, 起到保证整个廊道网络中几个重要斑块连通 的踏脚石作用。如果没有这些小面积斑块, 则廊道 会因斑块之间距离太远受到干扰被中断，因此这些 斑块的重要性也不容忽视。

\section{3 廊道的有效性和廊道宽度}

本研究表明夏季核心生境斑块4与 6,19 与 20 之 间存在多条廊道连接，另外大多相邻斑块对之间都 有可替代的廊道(图4)。Dutta等(2016)认为当有更多 的廊道可供选择时, 物种在景观中移动时有可选择 的替代路径, 可提高种群之间的连接性。本研究结 果表明保护区马可波罗盘羊生境斑块间的连通性 相对较好, 但有待进一步评估上述廊道的功能状况 和可利用性。建议当地政府在实验区建设检查站点, 以及在边境区域建设公安边防检查哨所时，尽量回 
避廊道所在区域和邻近区域。遗憾的是, 本文仅展 现了马可波罗盘羊的线性廊道，并未进一步计算廊 道的具体宽度, 今后在研究工作中设计生态廊道时, 要充分考虑多方面因素, 合理设计廊道宽度, 以避 免廊道过窄产生的边缘效应, 或廊道过宽导致物种 在生态廊道中移动缓慢。

\section{4 国道对生态廊道有效性的影响}

当核心生境斑块间的欧几里得距离较大或廊 道穿过河谷或交通道路时, 连接质量最低(Dutta et $\mathrm{al}, 2016)$ 。本研究中与国道314线相交的廊道质量均 很低(图4), 主要是因为道路的存在显著增大了盘羊 在斑块间迁移的阻力(Tischendorf \& Fahring, 2000), 使迁移难度大大增加, 不利于种群交流和扩散。当 生态廊道与交通线交叉时, 交叉区域会形成生态断 裂点, 生物难以跨越, 因车辆撞击导致的动物死亡 数量和概率也很高(池源等, 2015)。Schaller等(1987) 也曾指出随着喀喇昆仑公路的建成, 马可波罗盘羊 在保护区边界的巴基斯坦境内数量持续降低。诸多 研究表明, 道路对野生动物迁移具有明显的阻隔作 用, 且道路等级越高, 阻隔作用越大(李帅等, 2018)。因此需要重视生态断裂点的修复, 加快建设 下穿式和上跨式通道, 恢复和维持较高的景观连通 性，促进生境斑块间物质、能量和信息的正常流通。
保护区夏季斑块 20 与 24,17 与 20,15 与 26 之间的廊 道，冬季斑块 17 与 $20 ， 19$ 与 25 之间的廊道虽然没有 人为干扰，但廊道欧几里得距离较大，因此很容易 受到其他因素的影响而导致连接中断。保护区的盘 羊主要集中在西北部, 在今后廊道建设中应优先考 虑西北部各斑块之间的连通性，尤其是国道314线 两侧，其次考虑东南侧的潜在廊道区。国道314线 达布达尔、麻扎向南至红其拉甫边防哨所路段，历 史上记录有盘羊分布迁移跨越，因此可考虑在 G314线横切廊道处建设上跨式或者下穿式野生动 物通道(图6), 将两侧的马可波罗盘羊生境斑块连接 起来。

\section{5 本研究的理论预测、实用性分析与局限性}

本研究基于最小成本距离原理与电流理论的 Linkage Mapper模型模拟识别了马可波罗盘羊的潜 在生态廊道。与其他任何模型一样, 本研究由于建 模者的某些主观选择而存在局限性。虽然在研究区 存在很多潜在廊道，但并非本文所确定的所有廊道 都适合马可波罗盘羊迁移。由于没有指定任何最大 的廊道长度或成本，我们的连接分析只确定了一个 最好的连接选择，并没有进一步考虑盘羊能否在识 别的廊道中迁移。因此这里建议: (1)未来通过给盘 羊佩戴无线电跟踪项圈，精准筛选盘羊的迁移廊道;

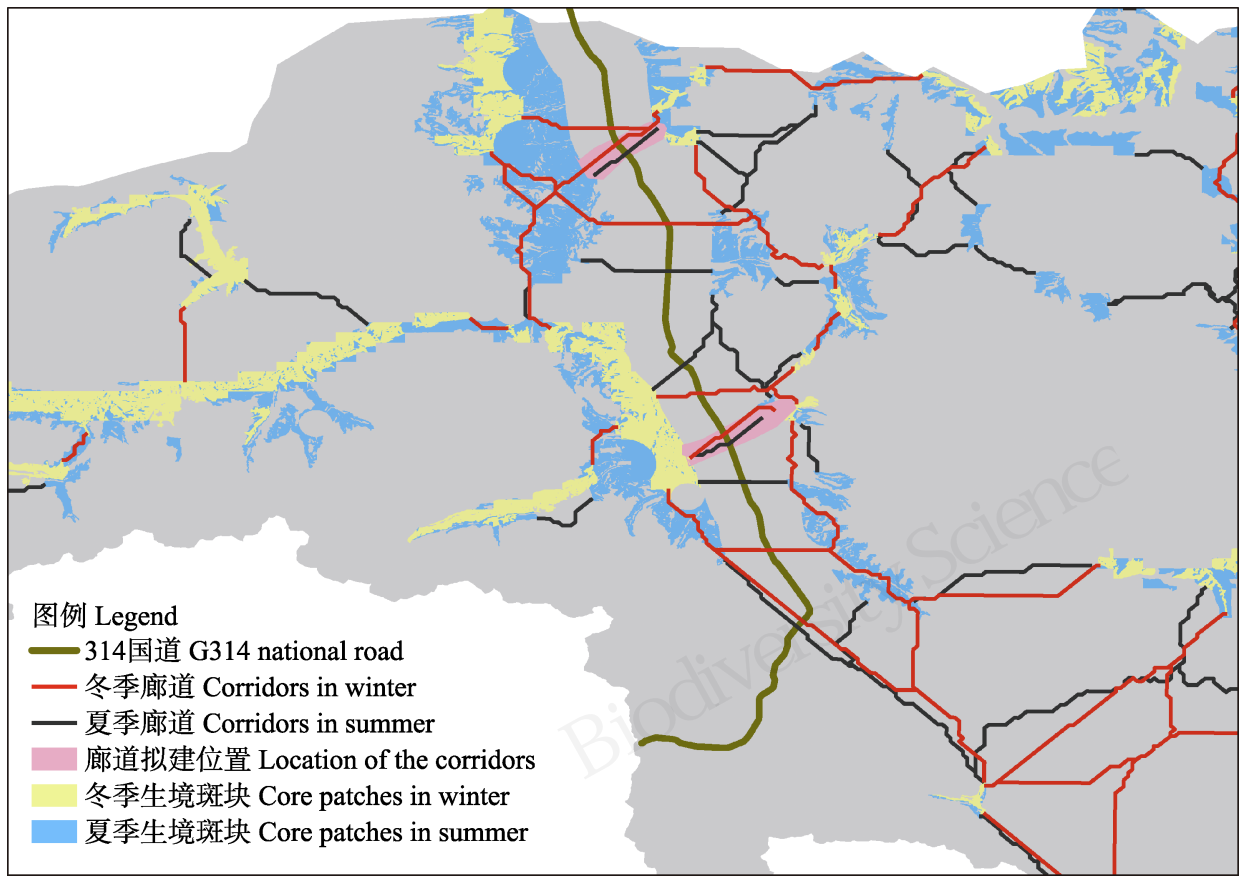

图6 塔什库尔干野生动物自然保护区内国道314线两侧拟建廊道位置

Fig. 6 Proposed corridor location on both sides of G314 in Taxkorgan Wildlife Nature Reserve 
(2)基于分子生物学手段测定各种群基因流, 以此判 断盘羊在各斑块间的迁移规律; (3)有必要赴实地验 证上述廊道是否有马可波罗盘羊存在和迁移。我们 所分析的景观要素均基于马可波罗盘羊的生境偏 好, 然而马可波罗盘羊很可能越过本研究区至保护 区外活动, 因此部分结果的准确性(例如中心性值) 可能会受到人为确定边界的影响。例如有些核心生 境斑块可能在更大尺度区域中非常重要, 但是在本 研究中因为处于保护区边缘而被判定为不重要的 斑块。研究区地形复杂, 受数据分辨率的影响, 某 些影响廊道分布的微地形、小尺度的水系分布等因 素可能被忽略, 这些因素都会在一定程度上影响廊 道模拟的结果。此外, 由于保护区内马可波罗盘羊 种群的健康发展不仅依赖于对保护区的有效管理 与保护, 亦更依赖于可持续稳定迁入/迁出保护区 的外部种群。因此为确保保护区内马可波罗盘羊种 群的持续健康发展, 今后研究工作中应更加注重大 尺度上马可波罗盘羊生态廊道的识别与分析，例如 保护区内与保护区外马可波罗盘羊的廊道识别, 中 国种群与阿富汗、巴基斯坦和塔吉克斯坦种群的跨 境廊道识别。另外, 保护区内与马可波罗盘羊同域 分布的野生动物还有雪豹、北山羊等, 维护马可波 罗盘羊迁移廊道对保护上述物种也至关重要。

致谢: 感谢塔什库尔干保护区管理局米鲁、依明江、 尔娃尔夏和周莉主任在野外调查中的大力支持和 帮助, 感谢喀什大学王玉涛教授对野外调查的指导 与帮助。

\section{参考文献}

Abrahms B, Sawyer SC, Jordan NR, McNutt JW, Wilson AM, Brashares JS, Hayward M (2017) Does wildlife resource selection accurately inform corridor conservation? Journal of Applied Ecology, 54, 412-422.

Adriaensen F, Chardon JP, De Blust G, Swinnen E, Villalba S, Gulinck H, Matthysen E (2003) The application of 'leastcost' modelling as a functional landscape model. Landscape and Urban Planning, 64, 233-247.

Allen CH, Parrott L, Kyle C (2016) An individual-based modelling approach to estimate landscape connectivity for bighorn sheep (Ovis canadensis). PeerJ, 4, 1-22.

Boyce MS, McDonald LL (1999) Relating populations to habitats using resource selection functions. Trends in Ecology \& Evolution, 14, 268-272.
Carroll C, McRae BH, Brookes A (2012) Use of Linkage Mapping and Centrality analysis across habitat gradients to conserve connectivity of gray wolf populations in western North America. Conservation Biology, 26, 78-87.

Chen QQ, Li ML, Han F, Wang MY, Xu WX, Yang WK (2018) Population survey of Ovis ammon polii in Taxkorgan Nature Reserve, Xinjiang. Sichuan Journal of Zoology, 37, 637-645. (in Chinese with English abstract) [陈强强, 李美 玲, 韩芳, 汪沐阳, 徐文轩, 杨维康 (2018) 新疆塔什库 尔干野生动物自然保护区马可波罗盘羊种群调查. 四川 动物, 37, 637-645.]

Chi Y, Shi HH, Feng AP (2015) Typical island landscape ecological network establishment-A case study of Chongming Island. Marine Environmental Science, 34, 433-440. (in Chinese with English abstract) [池源, 石洪华, 丰爱平 (2015) 典型海岛景观生态网络构建一一崇明岛为例. 海洋环境科学, 34, 433-440.]

Crooks KR, Sanjayan MA (2006) Connectivity conservation: Maintaining connections for nature. In: Connectivity Conservation (eds Crooks KR, Sanjayan M), pp. 1-20. Cambridge University Press, Cambridge.

Douglas-Hamilton I, Krink T, Vollrath F (2005) Movements and corridors of African elephants in relation to protected areas. Naturwissenschaften, 92, 158-163.

Dutta T, Sharma S, McRae BH, Roy PS, DeFries R (2016) Connecting the dots: Mapping habitat connectivity for tigers in central India. Regional Environmental Change, 16, 53-67.

Feng TT, Manen FT, Zhao NX, Li M, Wei FW (2009) Habitat assessment for giant pandas in the Qinling Mountain region of China. Journal of Wildlife Management, 73, 852-858.

Gong MH, Dai ZG, Zeng ZG, Zhang Q, Song YL (2007) A preliminary survey of population size and habitats of Marco Polo sheep (Ovis ammon polii) in Taxkorgan Nature Reserve. Acta Theriologica Sinica, 27, 317-324. (in Chinese with English abstract) [龚明昊, 戴志刚, 曾治高, 张琼, 宋 延龄 (2007) 新疆塔什库尔干自然保护区马可波罗盘羊 种群数量和栖息地初步调查. 兽类学报, 27, 317-324.]

Hashmi MM, Frate L, Nizami SM, Carranza ML (2017) Assessing transhumance corridors on high mountain environments by least cost path analysis: The case of yak herds in Gilgit-Baltistan, Pakistan. Environmental Monitoring and Assessment, 189, 488-497.

Jiang ZG, Jiang JP, Wang YZ, Zhang E, Zhang YY, Li LL, Xie F, Cai B, Cao L, Zheng GM, Dong L, Zhang ZW, Ding P, Luo ZH, Ding CQ, Ma ZJ, Tang SH, Cao WX, Li CW, Hu HJ, Ma Y, Wu Y, Wang YX, Zhou KY, Liu SY, Chen YY, Li JT, Feng ZJ, Wang Y, Wang B, Li C, Song XL, Cai L, Zang CX, Zeng Y, Meng ZB, Fang HX, Ping XG (2016) Red list of China's vertebrates. Biodiversity Science, 24, 501-551. (in Chinese and in English) [蒋志刚, 江建平, 王 跃招, 张鹗, 张雁云, 李立立, 谢锋, 蔡波, 曹亮, 郑光 美, 董路, 张正旺, 丁平, 罗振华, 丁长青, 马志军, 汤宋 
华, 曹文宣, 李春旺, 胡慧建, 马勇, 吴毅, 王应祥, 周开 亚, 刘少英, 陈跃英, 李家堂, 冯祚建, 王燕, 王斌, 李 成, 宋雪琳, 蔡蕾, 蔵春金金, 曾岩, 孟智斌, 方红霞, 平晓 鸽 (2016) 中国脊椎动物红色名录. 生物多样性, 24, 501-551.]

Jiang ZG, Ma Y, Wu Y, Wang YX, Feng ZJ, Zhou KY, Liu SY, Luo ZH, Li CW (2015) China's mammalian diversity. Biodiversity Science, 23, 351-364. (in Chinese with English abstract) [蒋志刚, 马勇, 吴毅, 王应祥, 冯祚建, 周开亚, 刘少英, 罗振华, 李春旺 (2015) 中国哺乳动物多样性. 生物多样性, 23, 351-364.]

Kanagaraj R, Wiegand T, Kramer-Schadt S, Goyal SP (2013) Using individual-based movement models to assess inter-patch connectivity for large carnivores in fragmented landscapes. Biological Conservation, 167, 298-309.

Khan B, Ablimit A, Khan G, Jasra AW, Ali H, Ali R, Ahmad E, Ismail M (2016) Abundance, distribution and conservation status of Siberian ibex, Marco Polo and Blue sheep in Karakoram-Pamir Mountain area. Journal of King Saud University - Science, 28, 216-225.

Knaapen JP, Scheffer M, Harms B (1992) Estimating habitat isolation in landscape. Landscape and Urban Planning, 23, $1-16$.

Lees AC, Peres CA (2008) Conservation value of remnant riparian forest corridors of varying quality for Amazonian birds and mammals. Conservation Biology, 22, 439-449.

Li S, Zhang XF, Shi JB, Dong SK, Gao XX (2018) Effects of highway from Inner Mongolia to Xinjiang on habitat suitability of ungulates in Alashan desert. Chinese Journal of Ecology, 37, 103-110. (in Chinese with English abstract) [李帅, 张相锋, 石建斌, 董世鬼, 高晓霞 (2018) 蒙新高 速公路对阿拉善荒漠区有蹄类野生动物生境适宜性的影 响. 生态学杂志, 37, 103-110.]

Li WP, Bao H, Zhang MH (2017) Habitat analysis and design of potential ecological corridors for Amur tiger in Northeastern China. Acta Theriologica Sinica, 37, 317-326. (in Chinese with English abstract) [李维平, 包衡, 张明海 (2017) 中国东北虎栖息地分析与潜在生态廊道构建. 兽 类学报, 37, 317-326.]

Liang GD (1984) The Taxkorgan Nature Reserve was established. Xinjiang Forestry, (5), 26. (in Chinese) [梁果栋 (1984) 塔什库尔干野生动物保护区成立. 新疆林业, (5), 26.]

Liu HM, Liu XM, Wang CZ, Wang Q (2016) Assessment and conservation strategy on habitat suitability of Syrmaticus humiae in Jinzhongshan National Nature Reserve. Journal of Geo-information Science, 18, 526-536. (in Chinese with English abstract) [刘慧明, 刘晓曼, 王昌佐, 王桥 (2016) 金钟山国家级自然保护区黑颈长尾雉生境适宜性评价. 地球信息科学学报, 18, 526-536.]

McRae BH (2012) Centrality Mapper Connectivity Analysis Software. The Nature Conservancy, Fort Collins.

McRae BH, Kavanagh DM (2011) Linkage Mapper Connectivity
Analysis Software. The Nature Conservancy, Fort Collins.

McRae BH, Shah VB (2009) Circuit Scape Users' Guide. The University of California, Santa Barbara.

Mi CR, Guo YM, Huettmann F, Han XS (2017) Species distribution model sampling contributes to the identification of target species: Take black-necked crane and hooded crane as two cases. Acta Ecologica Sinica, 37, 4476-4482. (in Chinese with English abstract) [宓春荣, 郭玉民, Huettmann F, 韩雪松 (2017) 基于物种分布模型的精确 采样提高目标物种发现率: 以黑颈鹤(Grus nigricollis)、白 头鹤(Grus monacha)为例. 生态学报, 37, 4476-4482.]

Pelletier D, Clark M, Anderson MG, Rayfield B, Wulder MA, Cardille JA (2014) Applying circuit theory for corridor expansion and management at regional scales: Tiling, pinch points, and omni directional connectivity. PLoS ONE, 9, e84135.

Pierik ME, Dell'Acqua M, Confalonieri R, Bocchi S, Gomarasca S (2016) Designing ecological corridors in a fragmented landscape: A fuzzy approach to circuit connectivity analysis. Ecological Indicators, 67, 807-820.

Qing J, Xu C, Yang B, Yang ZS, Qi DW, Yang XY, Gu XD, Dai Q (2016) Corridor design for the giant panda in the Xiaoxiangling Mountains. Acta Ecologica Sinica, 36, 1125-1133. (in Chinese with English abstract) [青菁, 胥池, 杨彪, 杨志松, 齐敦武, 杨旭显, 古晓东, 戴强 (2016) 小相岭山系大熊猫廊道规划. 生态学报, 36, 1125-1133.]

Salas EAL, Valdez R, Michel S (2017) Summer and winter habitat suitability of Marco Polo argali in southeastern Tajikistan: A modeling approach. Heliyon, 3, e00445.

Sawyer SC, Epps CW, Brashares JS (2011) Placing linkages among fragmented habitats: Do least-cost models reflect how animals use landscapes? Journal of Applied Ecology, 48, 668-678.

Schaller GB, Kang A (2008) Status of Marco Polo sheep Ovis ammon polii in China and adjacent countries: Conservation of a vulnerable subspecies. Oryx, 42, 100-106.

Schaller GB, Li H, Ta LP, Lü H, Ren JR, Qiu MJ, Wang HB (1987) Status of large mammals in the Taxkorgan Reserve, Xinjiang, China. Biological Conservation, 42, 53-71.

Smallwood P, Shank C, Dehgan A, Zahler P (2011) Wildlife Conservation ... in Afghanistan? BioScience, 61, 506-511.

Spear SF, Balkenhol N, Fortin M, McRae BH, Scribner KIM (2010) Use of resistance surfaces for landscape genetic studies: Considerations for parameterization and analysis. Molecular Ecology, 19, 3576-3591.

Tian B, Zhou YX, Zhang LQ, Ma ZJ, Yang B, Tang CD (2008) A GIS and remote sensing based analysis of migratory bird habitat suitability for Chongming Dongtan Nature Reserve. Acta Ecologica Sinica, 28, 3049-3059. (in Chinese with English abstract) [田波, 周云轩, 张利权, 马志军, 杨波, 汤臣栋 (2008) 遥感与GIS支持下的崇明东滩迁徙鸟类生 境适宜性分析. 生态学报, 28, 3049-3059.]

Tischendorf L, Fahring L (2000) On the usage and mea- 
surement of landscape connectivity. Oikos, 90, 7-19.

Titeux N, Dufrene M, Radoux J, Hirzel AH, Defourny P (2007) Fitness-related parameters improve presence-only distribution modelling for conservation practice: The case of the red-backed shrike. Biological Conservation, 138, 207-223.

Valdez R, Michel S, Subbotin A, Klich D (2016) Status and population structure of a hunted population of Marco Polo argali Ovis ammon polii (Cetartiodactyla, Bovidae) in Southeastern Tajikistan. Mammalia, 80, 49-57.

Wang YT, Dai ZG, Yang SJ, Luo YZ (2016) The distribution of Marco Polo sheep and their habitat vegetation dynamics in east Pamir. Acta Ecologica Sinica, 36, 209-217. (in Chinese with English abstract) [王玉涛, 戴志刚, 杨世杰, 罗玉柱 (2016) 东帕米尔高原盘羊分布与栖息地植被覆 盖时空变化. 生态学报, 36, 209-217.]

Wang ZQ, Chen ZC, Hao CY (2009) Breeding habitat suitability evaluation of red-crown crane in Zhalong National Nature Reserve by the method of habitat suitability index. Wetland Science, 7, 197-201. (in Chinese with English abstract) [王志强, 陈志超, 郝成元 (2009) 基于 HSI模型的扎龙国家级自然保护区丹顶鹤繁殖生境适宜 性评价. 湿地科学, 7, 197-201.]

Willis EO (1974) Populations and local extinctions of birds on Barro Colorado Island, Panama. Ecological Monographs, 44, 153-169.

Wu CG, Zhou ZX, Wang PC, Xiao WF, Teng MJ, Peng L (2009) Evaluation of landscape connectivity based on Least Cost Model. Chinese Journal of Applied Ecology, 20, 2042-2048. (in Chinese with English abstract) [吴昌广, 周 志翔, 王鹏程, 肖文发, 滕明君, 彭丽 (2009) 基于最小 费用模型的景观连接度评价. 应用生态学报, 20,
2042-2048.]

Yeganeh KZ, Faryadi S, Yavari A, Kamali Y, Shabani AA (2016) Habitat suitability \& connectivity of Alborz wild sheep in the east of Tehran, Iran. Open Journal of Ecology, 6, 325-342.

Yu YQ, Ji MZ, Liu CG, Li KC, Guo ST (2008) Geographical distribution and vicissitude of argali, Ovis ammon, in China. Biodiversity Science, 16, 197-204. (in Chinese with English abstract) [余玉群, 姬明周, 刘楚光, 李克长, 郭松涛 (2008) 中国盘羊的地理分布和历史变迁. 生物多样性, 16, 197-204.]

Zeller KA, McGarigal K, Whiteley AR (2012) Estimating landscape resistance to movement: A review. Landscape Ecology, 27, 777-797.

Zhuge HJ, Li XW, Zhang X, Gao F, Xu DH (2014) Identification and conservation assessment of suitable habitats for Tibetan antelope in the alpine desert, Qinghai-Tibet Plateau. Chinese Journal of Applied Ecology, 25, 3483-3490. (in Chinese with English abstract) [诸葛海锦, 李晓文, 张翔, 高峰, 许东华 (2014) 青藏高原高寒荒漠区藏羚适宜生 境识别及其保护状况评估. 应用生态学报, 25 , 3483-3490.]

Zhuge HJ, Lin DQ, Li XW (2015) Identification of ecological corridors for Tibetan antelope and assessment of their human disturbances in the alpine desert of Qinghai-Tibet Plateau. Chinese Journal of Applied Ecology, 26, 25042510. (in Chinese with English abstract) [诸葛海锦, 林丹 琪, 李晓文 (2015) 青藏高原高寒荒漠区藏羚生态廊道 识别及其保护状况评估. 应用生态学报, 26, 2504-2510.]

(责任编委: 蒋志刚 责任编辑: 问文杰) 